\title{
Viewpoint: Towards an IK-SCIE integrative model: A theoretical reflection on the agricultural college curriculum in Zimbabwe
}

\author{
Christopher Ndlovu, Angela James and Nadaraj Govender, \\ University of KwaZulu-Natal, South Africa
}

\begin{abstract}
Investment in agricultural training in Zimbabwe occurs against a backdrop of scarce resources. Therefore, an insight into the suitability and quality of the curriculum in agricultural colleges will benefit students, their communities and the nation at large. The curriculum is a key determinant of the quality of agricultural training. Researchers have argued that the curriculum in the agricultural colleges is largely based on the scientific knowledge system, representing the western worldview. Furthermore, this curriculum neither recognises the variations among the people with regard to their knowledge of agricultural practices, nor does it consider the different worldviews that students bring into the classrooms. Relevance in agriculture, like in any science subject, encourages students to participate in classroom processes more deeply, learning in their own ways and bringing together their ideas, interests and experiences. The incorporation of cultural practices into learning also facilitates environmental sustainability. This study explores several curriculum models to explore these claims and suggests an integrative indigenous knowledge-science (IK-SCIE) model that can be used in crafting a curriculum relevant for the contextual setting of Zimbabwe. Based on this theoretical reflection, it is recommended that if indigenous knowledge is integrated in the agricultural curriculum, more research on indigenous practices would be promoted, leading to acceptance, documentation and the possible integration of these indigenous practices, hence making them accessible to a larger readership.
\end{abstract}

Key words: agricultural training, curriculum, integrative model, indigenous knowledge, sustainability, integration and worldview.

\section{Introduction}

Agriculture forms the backbone of Zimbabwe's aspirations for economic development. It is not surprising, therefore, that Zimbabwe has invested heavily in agricultural training. This investment, however, has not translated into a visible proportional increase in agricultural production. In fact, agricultural production has been on a gradual decline since independence. Despite this continued decline, the curriculum has continued to reflect the western scientific knowledge systems and values whose relevance to the Zimbabwean context is debatable. The curriculum is the key determinant of the quality of agricultural training. Scholars like Mugwisi (2017) and Machingura and Mutemeri (2004) have argued that the curriculum that pertains to the agricultural colleges in Zimbabwe is largely based on the scientific knowledge system, representing the western worldview. Using the assertions of Emeagwali \& Dei (2014), Higgs (2016), and Msila and Gumbo (2016), they further claim that the agricultural college 
curriculum neither recognises the variations among the learners with regard to their knowledge of agricultural practices, nor the different worldviews that learners bring to the classrooms. Thus, it is imperative that a new relevant curriculum be developed that centralises and is informed by Zimbabwe's socio-economic and cultural needs and yet integrates some of the western scientific values to increase agricultural sustainability in the rural communities that are targeted by the agricultural colleges. Therefore, the purpose of this curriculum reflection is to create a pool of models from which one can extract appropriate dimensions to infuse and integrate into an eclectic curriculum development model that is consistent with the interpretivist perceptions of indigenous knowledge (IK) that can be used to develop an integrative agricultural college curriculum in Zimbabwe.

\section{Curriculum models}

The field of curriculum development boasts a host of successful curriculum models stretching from the early theorists such as Franklin Bobbitt (1924) to Ralph Tyler`s (1949) seminal work on curriculum development. Curriculum models help curriculum designers to systematically and transparently map out the rationale for the use of particular teaching, learning and assessment approaches (O’Neil \& Murphy, 2010). At the same time, it should be acknowledged that although curriculum development models are 'technically useful, they often overlook the human aspect such as the personal attitudes, feelings, values involved in curriculum making' (Ornstein \& Hunkins, 2009:15). Therefore, models presented in this study are analysed and the best practices for enhancing student learning are infused in the proposed eclectic curriculum development model. The study focuses mainly on the contributions of Tyler, Hilda Taba, Lawton and Stufflebeam as well as on Mthunzi's negotiated entrepreneurial curriculum.

\section{Tyler's curriculum model}

Ralph Tyler's (1949) curriculum model is typical of a product curriculum model. It is deductive in nature and primarily focuses on the objectives and the learner's experiences. It presents a triad of elements comprising leaner's objectives, experiences and evaluation. The model generates three main questions: (1) What are the main aims and objectives of the curriculum? (2) What experiences meet these aims? (3) How can the attainment of these objectives be evaluated? The key characteristics of Tyler's curriculum development model are presented in Figure 1.

This model has served as a basis for organising the curriculum for over 50 years in many developing countries, including Zimbabwe, and has resulted in the formulation of such models as Baker and Popham (1973), which have been criticised for their over emphasis on learning objectives and were viewed as employing very technical, means-to-end reasoning (O'Neil \& Murphy, 2010).

It must be admitted here that the Tylerist curriculum development model avoids general statements of intent. It provides clearly defined aims and objectives that are achievable. It allows for precise assessment and helps the teachers to clearly identify skills and competencies that need to be mastered. On the other hand, it is pertinent to argue that such objectives-based models 
minimise the significance of other contributory milestones in the development of a curriculum, such as the requisite inputs and processes which impact on the successful development of a curriculum. The model has also been criticised for trivialising and splitting issues, particularly at lower educational levels. The objectives themselves are sometimes difficult to develop and, in some instances, they discourage creativity as the learner is forced to narrowly focus on the stated objectives. Furthermore, this model advocates and enshrines the behaviourist psychology and philosophy to the exclusion of other progressive philosophies (Neary, 2002). Thus, the Tyler model and its subsequent branches perceive the curriculum from a positivist, deductive perspective and work from a basis of scientific management with a preference for education administrators developing the curriculum and having the teachers implement it. Thus, while useful in developing a positivist, deductive curriculum, a Tylerist deductive curriculum model fails to accommodate the perception of learning experiences as a social construct reflecting power and value conflicts that are a result of negotiations and persuasion. Despite its shortfalls as a development model, the objectives aspect of the Tylerist model will be accommodated in constructing the indigenous knowledge-science (IK-SCIE) curriculum model. These objectives will be used for providing guidelines for selecting learning activities and, subsequently, as the criteria for evaluation.

Figure 1. Characteristics of Tyler's curriculum model

1. The curriculum focuses on objectives, experiences and evaluation.

2. The language used is consistent with the model's behavioural philosophy.

3. The product outcomes have to be observable and measurable.

4. Learning is perceived as a change of behaviour.

5. The curriculum is deductive, starting from a conceived generalisation and progressing to specifics.

6. The curriculum is product-oriented and teacher-developed.

\section{Hilda Taba's curriculum model}

Another curriculum development model that is commonly applied in the development of most curricula is Hilda Taba's (1962) inductive curriculum development model that is typical of a process model. Neary (2002:39) described the process model as one which emphasises 'activities and effects'. Hilda Taba's model is inductive in nature, proceeding from specifics towards the general, unlike deductive models that start with the general and proceed to the specific. Knight (2001) observed that the inductive process models such as Hilda Taba's make logical sense in that what matters in learning and teaching is not so much the product on its own but the processes, messages and conditions. If these are in place, good outcomes will follow. On the same note, Hussey and Smith (2008) and Maher (2004) have extolled the advantages of such models. For example, Hussey and Smith (2008:367) maintain that:

accepting that learner motivation is an essential element in learning, we propose that those who teach should begin to reclaim learning outcomes and begin to frame them more broadly and flexibly, to allow for demonstrations and expressions of appreciation, enjoyment and even pleasure, in the full knowledge that such outcomes pose problems for assessment. 
Hilda Taba's model is linear and hierarchical, starting with the diagnosis of the learner's needs and the expectations of society. While the linearity aspect of the model would not be consistent with a negotiated IK-SCIE curriculum, it should be acknowledged that the aspect of addressing the needs of the learners and the society in which they operate will be acceptable to both a science-based curriculum and an IK-based curriculum. In essence, this translates into the involvement of the community and acceptance of community knowledge, its culture, values and beliefs. In the case of learners studying agriculture, for instance, it is imperative that their needs are addressed. Taba's model uses these identified needs to determine the objectives of the curriculum. The rest of the model focuses on the development process. The key steps in Hilda Taba's curriculum model are illustrated in Figure 2.

Figure 2. Stages in Taba's curriculum model

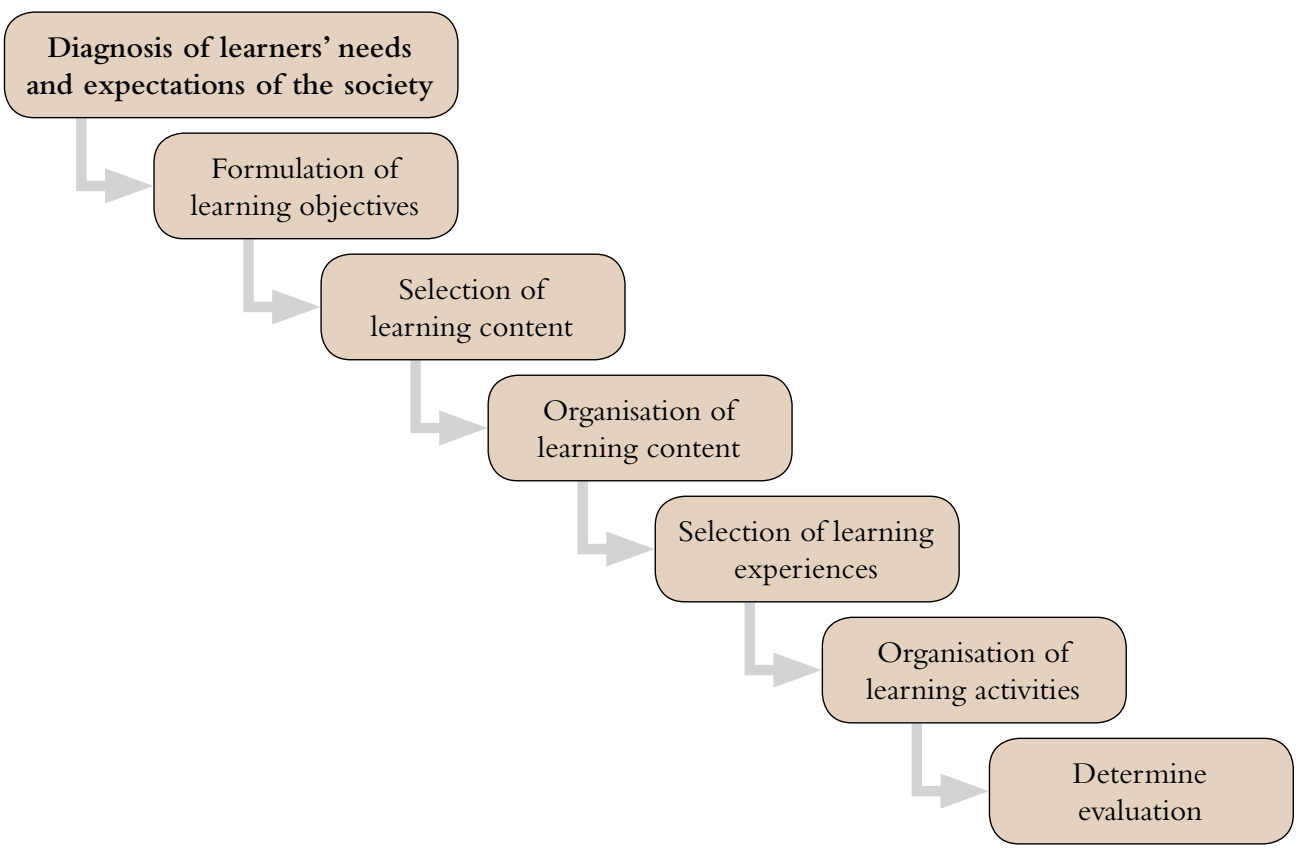

Hilda Taba's model tends to emphasise the learners' activities and emphasises the role of the teacher's knowledge, which is often Eurocentric to the exclusion of the communityconstructed knowledge of the learners. After all, most agriculture teachers, particularly in Zimbabwe, are products of the science-based curriculum that is deeply rooted in western behaviourist philosophy. While it is logical to involve the teachers in curriculum development, Taba's model over utilises and emphasises the teacher, whose understanding of divergent IK in some instances may be limited. This is pertinent in Zimbabwe's case, where teachers are products of a miscellany of cultures and backgrounds. In this study, teachers' knowledge would be utilised in the development of the curriculum that is at par with that of the indigenous communities' cultural practices. 
While this study perceives Taba's model as reflecting learner's needs and teacher's knowledge as reflected mainly in the western science-based curriculum, it appreciates the centralisation of the learner, albeit with supportive scaffolding from the community. The argument here is that learners on entry into colleges do have their own community-based knowledge which can be incorporated into the curriculum, as reflected in the constructivist school of thought. Thus, the learner's background knowledge will be integrated into the proposed curriculum framework. Another, key feature of the Hilda Taba curriculum that will be incorporated will be its inductive nature. As observed, deductive approaches tend to be rigid and give no room for a negotiated curriculum. The objectives, aims and knowledge values are pre-set and predetermined. In this study, the proposed curriculum framework allows for flexibility and negotiation as consistent with IK epistemology. Thus, from this model, the eclectic curriculum framework used will entail the determination of learner and societal needs. It will also be informed by Taba's process model, which identifies the learners' needs, selects the learning activities and reorganises the activities into usable integrated structures.

It should be noted that the stages subsequent to the interest of the learners include selection and organisation of content and learning experiences. These will be negotiated and confirmed by the community elders who, in most cases, are repositories of traditional knowledge. In the proposed curriculum framework, the approach will not necessarily be linear but may adopt a more reiterative approach.

IK is by its nature grounded in the epistemological perspective of knowledge as a social construct, and therefore a curriculum that aspires to infuse and integrate IK would not readily lend itself solely to a model that is grounded in the absolutist perspective such as the Tyler and Taba models of the curriculum development. Concurring with this view, Walker (1971:51) states that these 'classical models despite their success seem not to effectively represent the characteristics of traditional educational practice'. It is for this reason that this study would not solely adopt the otherwise classical curriculum models as presented by Ralph Tyler and Hilda Taba. This is consistent with Emeagwali's (2003:1) view that at the core of the mainstream of the western curriculum is a desire to negotiate nature through sequential processes such as hypothesis formulation, experiment and prediction'. An IK-SCIE curriculum will not readily fall into this presupposed 'neat linear' model of curriculum development.

\section{Lawton's selection from culture curriculum model}

Lawton (1973) developed his selection from culture curriculum in an effort to underplay the behaviourist-based objectives curriculum models as developed by Tyler (1949). In his model, the curriculum is perceived as a whole way of life of a society whose educational purpose is to select and transmit aspects of culture that are considered as most worthwhile and deserving of being passed on to the next generation (Emeagwali \& Dei, 2014). Lawton's selection from culture assumes that the teacher knows the worthwhile cultural aspects that need to be transmitted to the next generation. The assumption is that the teacher uses the knowledge of philosophy, psychology and sociology in making the selection of culture. In support of this approach, Stenhouse (1975) states that this selection from culture should result in worthwhile knowledge that should lead to societal betterment. Lawton's curriculum subdivides the culture into nine components (see Figure 3). 
Figure 3. Lawton's cultural analysis model

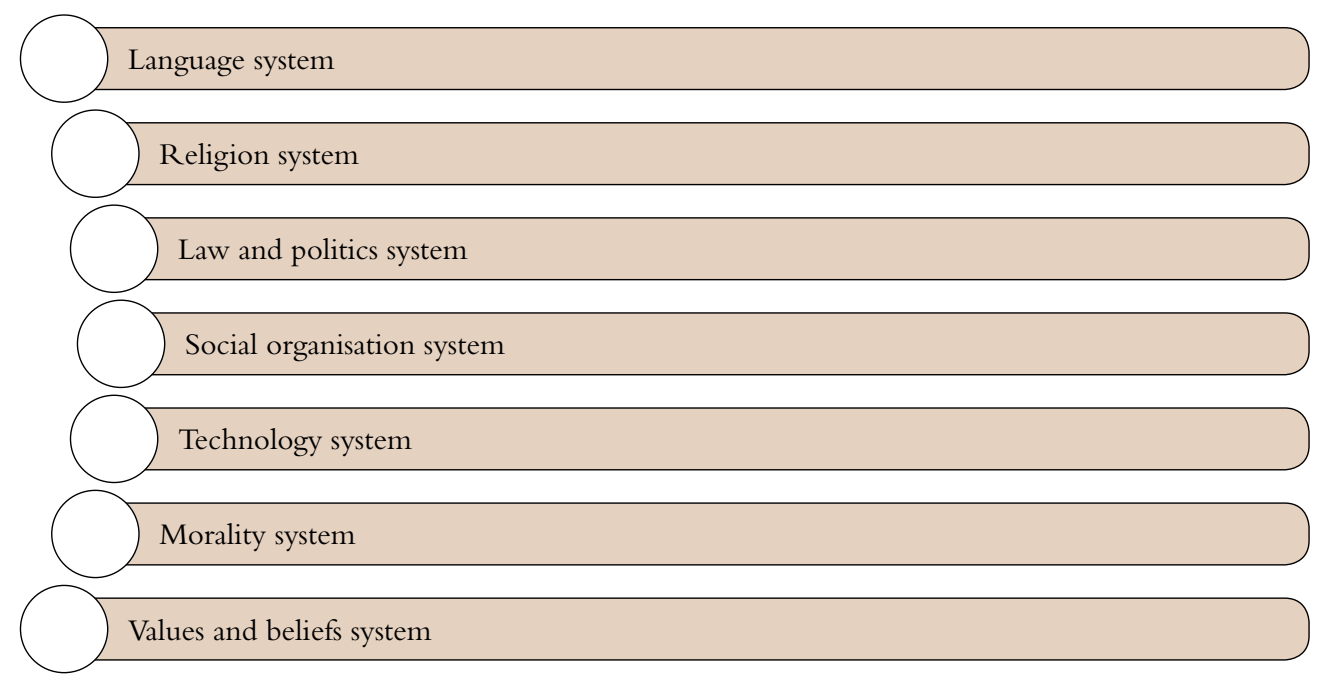

Lawton attempts to develop a curriculum that addresses all the key cultural dimensions that are global in nature. Lawton's nine systems help to ensure that as many cultural dimensions are taken aboard. Thus, the model will be used to ensure that all aspects of the cultural systems are included in the developed curriculum. Thus, in developing a negotiated curriculum taking aboard IK, it is important that the negotiation lens be broadened to include methodological and knowledge pluralism.

\section{Developing the curriculum using Stufflebeam's CIPP model}

Curriculum evaluation models are meant to explain the process of evaluating already existing programs. Stufflebeam's context, input, process and product evaluation (CIPP) model is 'a comprehensive framework for conducting formative and summative evaluations of project, personnel, products, organisations, and evaluation systems' (Stufflebeam \& Shinkfield, 2007:34). It originated in the late 1960s to provide greater accountability for the inner-city school district reform project in the United States. It was to address the limitations of traditional evaluation approaches (Stufflebeam, 1971). The CIPP evaluation model 'is configured especially to enable and guide comprehensive, systematic examination of socially and educational projects that occur in the dynamic, septic conditions of the real world' (Stufflebeam \& Shinkfield 2007:35).

The Stufflebeam's CIPP model is made up of four components which are very significant in the curriculum development processes: context evaluation, input evaluation, process evaluation and product evaluation. According to Stufflebeam (2003), the objective of context evaluation is to assess the overall environmental readiness of the curriculum, examine whether existing goals and priorities are attuned to the needs of the community and learners, and assess whether proposed objectives are sufficiently responsive to assessed needs. The purpose of an input evaluation is to help prescribe a programme by which to make needed changes. During input evaluation, experts, evaluators and stakeholders identify or create potentially 
relevant approaches. Then, they assess the potential approaches and help formulate a responsive plan. Process evaluation affords opportunities to assess periodically the extent to which the curriculum is being carried out appropriately and effectively. Product evaluation identifies and assesses curriculum outcomes, both intended and unintended.

Stufflebeam and Shinkfield (2007) suggest that a combination of techniques should be used to assess a comprehensive set of outcomes. Doing so helps to cross-check the various findings. However, the product evaluation is a key feature of all technocist curriculum models and since the intended curriculum is an IK curriculum, its focus must necessarily be on community consensus and validation more than on assessing the attainment of predetermined objectives. In fact, it is argued here that the key determinant of the curriculum development model to be used in this study is the nature of IK. IK forms an indivisible, integral part of a society's culture, values, norms, beliefs and rules.

In this study, unlike in the other instances where the Stufflebeam's model has been used for evaluation purposes, some aspects of the model will be used to ensure a sequential development of the curriculum. It is the view in this study, that if a model can logically and sequentially evaluate a programme, it is only proper to assume that the same model can be used to develop a new curriculum or modify an existing one. This study believes that certain benefits are realised from using the same model for curriculum development and evaluation, especially when the framework from the curriculum evaluation is grounded in the curriculum for development. The CIPP model is uniquely ideal for development of an IK-SCIE curriculum by evaluating the current agricultural curriculum, as its most fundamental tenet is 'not to prove but improve existing programmes' (Stufflebeam \& Shinkfield, 2007:329). Table 1 shows how the study intends using some aspects of the model for curriculum development instead of curriculum evaluation.

The CIPP model, while providing a logical sequential curriculum development model, tends to be too positivist and technocist, and is likely to produce a curriculum that is absolutist, linear and traditional in orientation. The resultant curriculum is likely to 'be informed by the theory of linear articulation' (Mthunzi, 2001:292), which assumes a linear curriculum development process. In this light, it will be inconsistent with IK epistemology to solely rely on and utilise the CIPP model in the development of the IK-SCIE-based curriculum. As Urevbu (1985:15) aptly observed, 'Most central questions of curriculum are normative in the sense that they involve choices among many competing values.'Thus, the CIPP model will be used conjointly with other models discussed. In essence, therefore, the intended IK-SCIE curriculum will be developed following the stages as presented by Stufflebeam, but also incorporating models already discussed above. Thus, the curriculum model to be used will be eclectic in nature and not based on one model. 
Table 1. The Stufflebeam components to be used in curriculum development

\begin{tabular}{|c|c|c|}
\hline $\begin{array}{l}\text { CIPP model } \\
\text { component }\end{array}$ & Use for curriculum development & Use for curriculum evaluation \\
\hline Context & $\begin{array}{l}\text { To define the operating context within } \\
\text { which the curriculum will be delivered. } \\
\text { Determine the specific characteristics of } \\
\text { the learners. To establish a rationale for the } \\
\text { determination of the curriculum objectives. }\end{array}$ & $\begin{array}{l}\text { To define the environment } \\
\text { relevant to the curriculum, } \\
\text { describing the actual and intended } \\
\text { conditions of the programme, } \\
\text { identifying unmet needs, and } \\
\text { diagnosing barriers that prevent } \\
\text { needs from being met. }\end{array}$ \\
\hline Input & $\begin{array}{l}\text { To identify and assess the capabilities, } \\
\text { strategies, and designs available for } \\
\text { implementing the curriculum as related to } \\
\text { the to the curriculum's objectives. Determine } \\
\text { what internal resources are needed to } \\
\text { enable achievement of the objectives and to } \\
\text { search for external resources when required. } \\
\text { Also, the input phase considers the cost to } \\
\text { implement the curriculum. }\end{array}$ & $\begin{array}{l}\text { To determine the extent that } \\
\text { available resources were used to } \\
\text { achieve the curriculum objectives. }\end{array}$ \\
\hline Process & $\begin{array}{l}\text { To identify the procedural design that will } \\
\text { be used to implement the curriculum. } \\
\text { The curriculum objectives are translated } \\
\text { into specific activities that constitute the } \\
\text { instructional design. }\end{array}$ & $\begin{array}{l}\text { To identify deficiencies in } \\
\text { the procedural design or in } \\
\text { the implementation of the } \\
\text { curriculum, i.e. what actually } \\
\text { took place during instruction? } \\
\text { To provide information necessary } \\
\text { to make modifications to the } \\
\text { implementation strategies used } \\
\text { during instruction. To maintain } \\
\text { procedural documentation. }\end{array}$ \\
\hline
\end{tabular}

Source: Stufflbeam and Shinkfield (2007)

\section{Mthunzi's entrepreneurial curriculum model}

Mthunzi (2001) argues that the current curriculum projects 'the acquisition of traditional academic conformist attributes and skills'. According to him, the traditional curriculum is based on the assumption of an educated individual as one having a mastery of information, facts and knowledge, able to critique and analyse and reproduce what has been learnt. The teaching and learning strategies are those that centralise the enhanced teacher authority and monologise the process of learning. As a challenge to the traditional curriculum, he proposes a theoretical curriculum framework that embodies a triad equi-projection of entrepreneurial attributes and skills, academic knowledge and self-management skills. Mthunzi (2001) presents a comparative theoretical paradigm that reflects the key characteristics of his intended curriculum (see Table 2).

However, an omission in the model is the absence of IK and its lack of clear developmental stages. In the place of IK, the model emphasises entrepreneurial skills. It is for this reason that the model on its own remains inadequate and it is in this light that the research proposes an 
eclectic model that takes cognisance of values as expressed by the interpretivists and absolutists. The proposed eclectic curriculum model allows for a negotiated IK-SCIE curriculum that is informed by both the western scientific approach and the indigenous knowledge systems (IKS), capable of demonstrating 'autopoiesis' (Govender, 2012:113). It is in this vein that this study proposes the use of an eclectic curriculum framework to develop the IK-SCIE curriculum for the agricultural college.

Table 2. A comparative analysis of Mthunzi's model and the traditional objectives-based model

\begin{tabular}{|l|l|l|}
\hline $\begin{array}{l}\text { Curricular } \\
\text { characteristics }\end{array}$ & Traditional paradigm & Proposed paradigm \\
\hline Epistemology & Reductionist & Constructivist \\
\hline Knowledge & $\begin{array}{l}\text { Transferred in its totality from } \\
\text { teacher to student and sustained } \\
\text { through memorisation, regurgitation } \\
\text { and fear of failure }\end{array}$ & $\begin{array}{l}\text { Negotiated and reconstructed } \\
\text { through students and teacher } \\
\text { experiences. Knowledge in } \\
\text { constant flux }\end{array}$ \\
\hline Knowledge utility & $\begin{array}{l}\text { Reproduced undigested and } \\
\text { non-utilitarian }\end{array}$ & $\begin{array}{l}\text { Recreated and sourced for a specific } \\
\text { utilitarian purpose }\end{array}$ \\
\hline Key attributes & Critiquing, analysis and conformity & $\begin{array}{l}\text { Confidence, creativity, innovativeness } \\
\text { and self-autonomy }\end{array}$ \\
\hline Pedagogical focus & Examination-oriented & Non-examinable, self-management \\
\hline $\begin{array}{l}\text { Teaching } \\
\text { approaches }\end{array}$ & $\begin{array}{l}\text { Teacher-centred; teacher as subject } \\
\text { expert, passive participation by } \\
\text { students }\end{array}$ & $\begin{array}{l}\text { Teacher as part of networking, } \\
\text { teamwork, investigative, experiential } \\
\text { and active participation by students }\end{array}$ \\
\hline $\begin{array}{l}\text { Classroom } \\
\text { dynamism }\end{array}$ & $\begin{array}{l}\text { Rigidity in learning environment, } \\
\text { schedules, timetabling, rooms, } \\
\text { teachers and student positions }\end{array}$ & $\begin{array}{l}\text { Flexibility in learning environment, } \\
\text { schedules, timetables, modules }\end{array}$ \\
\hline Articulation & $\begin{array}{l}\text { Disjunction between school and } \\
\text { community }\end{array}$ & $\begin{array}{l}\text { Consonance between school and } \\
\text { community }\end{array}$ \\
\hline $\begin{array}{l}\text { Devolution of } \\
\text { power }\end{array}$ & $\begin{array}{l}\text { Teacher has power, exercises } \\
\text { authority and control }\end{array}$ & $\begin{array}{l}\text { Individual learner is empowered to } \\
\text { learn, community contributes }\end{array}$ \\
\hline Source
\end{tabular}

Source: Mthunzi (2001)

\section{IK-SCIE curriculum: A proposed eclectic framework}

IK forms an indivisible, integral part of a society's culture, values, norms, beliefs and rules. Consistent with the nature of culture, it is 'a complex, nonlinear, dynamic with multiple feedback loops' (Govender, 2012:125). Lawton (1986) also posits that a curriculum is a selection from culture and is therefore deeply rooted in culture. Thus, a study of the curriculum should necessarily involve an analysis of the power conflicts, values and contentions within the competing cultures. If the current Eurocentric science-based curriculum is to be meaningfully analysed with the intention of developing a negotiated IK-SCIE curriculum that is informed 
by both the western scientific approach and the IKS capable of demonstrating autopoiesis (self-generation), it is imperative that it be analysed, interpreted and formulated within the complexity curriculum framework as presented in Figure 4 below.

The proposed study framework is eclectic in that it acknowledges that existing individual curriculum models that are Eurocentric and technocist cannot on their own provide an adequate framework for developing an IK-SCIE curriculum. It therefore incorporates various aspects from different models (see Figure 4).

Figure 4. A proposed eclectic curriculum development framework

\section{Contextual analysis zone \\ Identification of leverage \\ change points, integration of \\ science-based and indigenous \\ knowledge, and competencies}

\section{Curriculum reconceptualisation zone \\ Formulation of design}

Curriculum principles for IK-SCIE

regenerative zone curriculum and

Negotiation of values, ethics, implementation strategies

social rules, power relations,

epistemology, competencies

The proposed eclectic framework assumes a triad of research events: the contextual analysis zone of the reductionist science-based curriculum, the curriculum regenerative zone and the curriculum reconceptualisation zone.

\section{The contextual analysis zone}

At the contextual analysis zone, micro curriculum analysis is carried out to identify key leverage points of change and transformation. This zone determines the areas of weaknesses, tension and points of exclusion within the existing science-based curriculum. In this zone, Stufflebeam's CIPP stages will be used to ensure that all the curriculum development aspects have been examined and the weaknesses and strengths identified. The justification for the use of the CIPP model in this zone is that it covers all the curriculum development stages. It thus allows for areas of strength and weakness to be exposed in the whole process - unlike the Tylerist model, which would focus on the product to the exclusion of the process. However, the model, being positivist, may not be able to reflect underlying conflicts of control and power struggles within 
the curriculum. Sources of power struggle, tension and points of change will be identified through intepretivist approaches which will allow for the quantifiable data to be analysed further using the intepretivist approach (see Figure 5).

Figure 5. The interpretivist approach

\begin{tabular}{|l|l|l|}
\hline $\begin{array}{l}\text { Objectivist } \\
\text { dimension }\end{array}$ & $\begin{array}{l}\text { Interpretation and construction } \\
\text { of reality as the curriculum is } \\
\text { negotiated and mapped against } \\
\text { dimension } \\
\text { quantifiable data based } \\
\text { on the CIPP model } \\
\text { of the commulues and epistemology } \\
\text { Mthunzi and Lawton's models }\end{array}$ & $\begin{array}{l}\text { Generalised beliefs } \\
\text { drawn concerning IKS } \\
\text { curriculum efficacy, } \\
\text { efficiency and cultural } \\
\text { relevance based on } \\
\text { IKS theories and } \\
\text { epistemology }\end{array}$ \\
\hline $\begin{array}{l}\text { Interpretationist } \\
\text { dimension }\end{array}$
\end{tabular}

The interpretationist dimension provides an analysis arena where the data generated regarding the existing curriculum will be further interrogated, interpreted and constructions of reality made rather than making simple recordings of objective and observable quantifications of data which would have been done at the objectivist tier. At this level, the values, attitudes and perceptions of the key players in the curriculum are analysed.

The global dimension assessment, the third dimension, includes implementers' and learners' judgements, behaviour and attitudes towards the curriculum. At this dimension, analysis is made of the individual's generalised beliefs and opinions about the efficiency, efficacy and cultural relevance, utility and impact of the existing curriculum. Despite the fact that the conceptual representation tends to be linear, the actual analysis may be reiterative and thus necessarily untidy and not linear.

\section{The curriculum regenerative zone}

The curriculum regenerative zone will be used as the zone of negotiating the infusion and integration of IK attributes, including the overarching values, ethics, social rules and power relations and the dominant features such as bodies of knowledge, attitudes, skills and competencies. At this stage, the representatives of the community present their perceptions of what should comprise a curriculum for agriculture. In this case, they determine the content, the activities and experiences they consider relevant to their communities. In essence, they provide their own perception of what they consider worthwhile in agriculture. They define the community knowledge and skills as they perceive them. At this stage, the curriculum model used will be Mthunzi's (2001) model that perceives knowledge as a social construct. This is consistent with the worldview theory that recognises that learners construct knowledge from their own social cultural experiences. Ogunniyi (2003) and Jegede (1996) have argued that learners' understanding of any new meaning is strongly influenced and determined by prior knowledge that in turn is determined by cultural beliefs, traditions and customs governed by a worldview. Knowledge according to this model is negotiated and reconstructed through 
community experiences. Knowledge is in a state of flux and is not permanent and as such can be sourced for use and application. Semali and Kincheloe (1999) also argue that understanding knowledge as changing and evolving is of particular interest in research involving IK, which is sometimes thought to be lacking in dynamism. This increases articulation between the school and the community and the ease of transfer of knowledge between them. In this model, it is the community that has the ownership of knowledge, unlike in the Hilda Taba models where the teacher is the kingpin in the determination of what is worthwhile knowledge. Elements of Lawton's model of selection of curriculum content from a culture will be used to ensure that the curriculum is not narrowed down.

\section{The reconceptualisation zone}

The third envisaged stage is the curriculum reconceptualisation zone. At this stage, infusion and integration will be carried out. This stage is consistent with the worldview epistemological perception, whose fundamental epistemological posit is that people understand and interpret what they perceive to be reality from different perspectives based on their values, norms, ethics and beliefs. People from different geographical locations and cultures tend to differ in their perceptions of the world and its processes. Kawagley (1995) states that the concept of the worldview is very closely related to the definitions of the culture and cognitive maps that different people possess. Kawagley (1995:8-9) further states that

among the indigenous cultures the worldviews include values, traditions, customs, myths, legends, stories, family, community and examples set by community leaders, a summation of coping devises that have worked in the past and may or may not be as effective in the present.

Consistent with this theory, this study acknowledges that different communities among indigenous cultures tend to have their own worldviews, unlike the conventional scientific worldview which tries to unify all world views.

These fundamental beliefs about the world then exert a powerful influence on how sense is made of world events. Thus, if an indigenous learner is to benefit from the curriculum, it must necessarily reflect his/her indigenous context. Since individuals have many ways of perceiving nature, science, the surrounding world and their place in it, understanding science concepts depends on their worldview (Odegaard, 1999). In such a scenario, three pertinent issues arise, namely, whether the curriculum accommodates differences in the worldviews, accepts negotiated responses, and how the curriculum accommodates different ideas and beliefs such as IK.

It is at this reconceptualisation zone that the two bodies of knowledge - western science and IKS are integrated to form a single holistic body of content. This is the stage where mitigating strategies for implementation will be developed. At this stage, community and college experts may validate the soundness and efficacy of the newly developed IKS programme. This study calls for a theoretical framework that views IKS and western science not as two diametrically opposed poles but rather as equal and complementary cosmologies. These, 'when carefully analysed, can be harmonized, infused and integrated into an IK-SCIE curriculum that embraces the tenets and synergies from both worlds', as proposed by Ogunniyi (2003:12) in his argumentation theory. 
IK-SCIE education is based on theories of learning developed from the cross-cultural perspective. According to this view, for most students the transition from their life-world into the science classroom is a cross-cultural experience (Aikenhead \& Jegede, 1999). With this thought, this study would make use of some learning theories informed by, among others, post-colonial theory (Carter, 2006), worldview theory (Kawagley, 1995) and social cultural theory (Bandura, 1977). These theories would be relevant in studying how IK is experienced and learnt in the field. The common thread that runs across these theories is that they acknowledge there are multiple ways of knowing and all should be given time and space in our educational curricula/institutions.

At the reconceptualisation stage, the western science content of the curriculum will be re-assessed to identify and weed out those bodies of knowledge, skills, attitude and competencies that, in line with post-colonial theory, are not consistent with the values of the society. According to Carter (2006), post-colonial theory is a theoretical tool that opens channels for revising philosophical frameworks that no longer work well in a post-colonial environment. Odora-Hoopers (2002) posits that the post-colonial theory is an examination of the impact and continuing legacy of the western conquest, colonisation and domination of non-western lands, students and cultures. On the other hand, Mansour (2008) argues that post-colonial theory is an engagement framework on issues like power structures and social hierarchies, with an emphasis on the inclusion of other forms of knowledge such as IK. Supporting the use of this theory in the study of IK, Dei (2000) states that there should be a hybridisation of knowledge bases in the educational curricula. Furthermore, Martin (2007:42) contends that

post-colonial theory has the potential of ushering in new models of education that embrace multiculturalism, engage diverse ways of knowing and ensure that the curricula are relevant and sustainable to a specific cultural and community setting.

An IK curriculum should of necessity be embedded in socio-cultural theories. At the reconceptualisation stage, the socio-cultural aspects will be sourced from the local society and its culture consistent with Vygotsky's socio-cultural theory, which states that 'the mechanism of individual development change is rooted in society and culture' (Vygotsky, 1978:7). This implies that thought and knowledge are not free from social and cultural influences. The sociocultural theory is widely applicable across disciplines and can be useful in the study of IK and science education. Lemke (2001) stresses that the use of socio-cultural theory enables us to view dynamic processes, such as human social activities, occurring within agricultural institutions. The theory is also of particular importance in social research as it acknowledges change and the evolution of knowledge in time and space. This study makes use of the social cultural theory to enable the researcher to appreciate the nature of IK and its attachment to the dynamic social and cultural processes of indigenous people.

\section{Conclusion}

The IK-SCIE integrative agricultural college curriculum model outlined in Figure 3 is embedded in the complexity theory. As Davis, Phelps and Wells (2004) assert, complexity is concerned with 
non-linear dynamics, emergence and self-organisation. It is a formal attempt to explore how simple, sometimes non-purposive, components in a system can self-organise, emerge or evolve into a coherent purposive and complex whole. Similarly, the IK-SCIE integrated agricultural college curriculum model proposed in this study is not linear and neither is it arboreal. It observes a major tenet of the complexity theory - as propounded by Govender (2012), Johnson and Christenson (2001), Sanford and Hopper (2009), Salen (2008) and Salen, Tekinbas and Zimmerman (2004) that a curriculum that is rooted in the complexity theory must of necessity immerse itself in the communities in which it is expected to operate. The proposed curriculum model looks up to the community elders, the college learners, college lecturers and Agritex Officers ${ }^{1}$ for its creation. It thus becomes a product of interaction, persuasion and negotiation.

\section{Endnote}

1. Agricultural Technical and Extension Services Officers are trained in agricultural colleges to assist communal farmers with following scientific farming methods.

\section{Notes on the contributors and their contributions}

\section{Lead author}

Ndlovu, Christopher I University of KwaZulu-Natal, South Africa

ORCID 0000-0003-1758-6055 | chrisndlovu47@gmail.com

Christopher Ndlovu, a National Institute of Humanities and Social Sciences (NIHSS)funded scholar, is currently a senior lecturer in the Department of Educational Foundations at Lupane State University, Zimbabwe. His key research areas include indigenous knowledge systems, curriculum innovations and contextualisation, environmental management and rural learning ecologies. He wrote this paper while affiliated with the University of KwaZulu-Natal, South Africa.

\section{Co-author}

James, Angela | University of KwaZulu-Natal, South Africa

ORCID 0000-0003-4644-1373 | Jamesa1@ukzn.ac.za

Angela James is a senior lecturer in Science Education in the School of Education at the University of KwaZulu-Natal. Her pedagogy is informed by phronesis, that is, problem-solving in authentic contexts where meaning is created and competence developed. Her research interests include research and service-learning, professional development of student teachers, and science and culture.

\section{Co-author}

Govender, Nadaraj | University of KwaZulu- Natal, South Africa

ORCID 0000-0002-3406-0605 | Govendern37@ukzn.ac.za

Nadaraj Govender is Associate Professor in Science Education at the School of Education, University of KwaZulu-Natal. His published research has covered indigenous knowledge 
systems (IKS) and the integration of IKS with science education, amongst other topics. He currently holds an NRF C2 rating. His research interests include physics/science education and IKS.

\begin{tabular}{|l|l|l|}
\hline Areas of contribution & Authors & $\begin{array}{l}\text { Percentage } \\
\text { contribution }\end{array}$ \\
\hline \multirow{3}{*}{$\begin{array}{l}\text { Conception or design of the paper, theory } \\
\text { or key argument }\end{array}$} & C. Ndlovu & $50 \%$ \\
\cline { 2 - 3 } & A. James & $25 \%$ \\
\cline { 2 - 3 } & N. Govender & $25 \%$ \\
\hline \multirow{2}{*}{ Drafting the paper } & C. Ndlovu & $60 \%$ \\
\cline { 2 - 3 } & A. James & $20 \%$ \\
\cline { 2 - 3 } & N. Govender & $20 \%$ \\
\hline \multirow{2}{*}{ Critical review of paper } & C. Ndlovu & $30 \%$ \\
\cline { 2 - 3 } & A. James & $40 \%$ \\
\cline { 2 - 3 } & N. Govender & $30 \%$ \\
\hline
\end{tabular}

\section{References}

Aikenhead, G.S. \& Jegede, O.J. (1999). Cross-cultural science education:A cognitive explanation of a cultural phenomenon. Journal of Research in Science Teaching, 36(3), 269-287.

Bandura, A. (1977). Self-efficacy: Toward a unifying theory of behavioural change. Psychological Review, 84(2), 191-215.

Baker, E.L., \& Popham, W.J. (1973). Expanding dimensions of instructional objectives. Englewood Cliffs, NJ: Prentice-Hall.

Bobbitt, J.F. (1924). How to make a curriculum. Boston, MA: Houghton Mifflin.

Carter, L. (2006). The challenges of post-colonialism to science education. Educational Philosophy and Theory, 38(5), 677-692.

Davis, B., Phelps, R. \& Wells, K. (2004). Complicity: An introduction and a welcome. Complicity: An International Journal of Complexity and Education, 1(1).

Dei, G.J.S. (2000). African development: The relevance and implications of 'indigenousness'. In G.J.S. Dei, B.L. Hall \& D. Goldin Rosenberg, (Eds), Indigenous knowledge in global contexts: Multiple readings of our world (pp. 70-88). Toronto: University of Toronto Press.

Emeagwali, G. (2003). African Indigenous Knowledge Systems (AIK): Implications for the curriculum. In T. Falola (Ed.), Ghana in Africa and the world: Essays in honour of Adu Boaheu. New Jersey: Africa World Press.

Emeagwali, G. \& Dei, G.J.S. (2014). African indigenous knowledge and the disciplines. Springer.

Govender, N. (2012). Educational implications of applying the complexity approach to Indigenous Knowledge Systems (IKS). Alternation, 19(2), 112-137. 
Higgs, P. (2016). African philosophy and the decolonisation of education in Africa: Some critical reflections. Educational Philosophy and Theory, 44(2), 37-55.

Hussey, T. \& Smith, P. (2008). Learning outcomes: A conceptual analysis. Teaching in Higher Education, 13(1), 107-115.

Jegede, O.J. (1996). Cross-cultural science education: A cognitive explanation of a cultural phenomenon. Journal of Research in Science Teaching, 36(3), 269-287.

Johnson, B. \& Christensen, L. (2001). Educational research: Quantitative and qualitative approaches. Boston, MA: Allyn \& Bacon.

Kawagley, O. (1995). A Yupiaq worldview. Prospect Heights, IL: Waveland Press.

Knight, P.T. (2001). Complexity and curriculum: A process approach to curriculum making, Teaching in Higher Education, 6(3), 369-381.

Lawton, D. (1973). Social change, educational theory and curriculum planning. London: Hodder and Stoughton.

Lawton, M.P. (1986). Environment and aging. Center for the Study of Aging.

Lemke, J.L. (2001). Articulating communities: Sociocultural perspectives on science education, Journal of Research in Science Teaching, 38(3), 296-316.

Machingura, V. \& Mutemeri, J. (2004, September). Towards a paradigm shift: Incorporating indigenous epistemologies in primary school education. Paper presented at the Kenton Khalamba Conference, Cathedral Peak, KwaZulu-Natal.

Mansour, S. (2008). An empirical study to measure students' learning performance using role playing serious games. Paper presented at the 12th International Conference on Computer Games: AI, Animation, Mobile, Interactive Multimedia \& Serious Games, Louisville, KY.

Martin, T. (2007). Amy Ashwood Garvey: Pan Africanist, feminist and Mrs Garvey No. 1 or a tale of two Amies? Dover, MA:The Majority Press.

Mugwisi, T. (2017). Applying indigenous knowledge in agricultural extension, the case of Agritex workers in Zimbabwe. Indilinga: African Journal of Indigenous Knowledge Systems, 16(1), $1-30$.

Mthunzi, C.G. (2001). Towards a conceptual entrepreneurial curriculum: Images and conceptions of an entrepreneur in Botswana senior secondary schools. Mosenodi, 10(1), 28-42.

Neary, M. (2002). Curriculum studies in post-compulsory and adult education. Cheltenham: NelsonThornes.

Ogunniyi, M.B. (2003). Traditional cosmology and science education. In M.B. Ogunniyi \& K. Rochford (Eds), The pursuit of excellence in science and mathematics education (pp. 22-30). Cape Town: University of the Western Cape.

Odegaard, C.V. (1999). Indigenous life projects and extractivism: Ethnographies from South America. Bergen: University of Bergen

Odora-Hoppers, C.A. (2002). Indigenous knowledge and the integration of knowledge systems:Towards a philosophy of articulation. Cape Town: New Africa Books.

O’Neil, G. \& Murphy, F. (2010). Guide to taxonomies of learning. UCD Teaching and Learning/ Resources. Retrieved from: http://www.ucd.ie/t4cms/ucdtla0034.pdf 
Ornstein, A. \& Hunkins, F. (2009). Curriculum: Foundations, principles, and issues. Boston, MA: Allyn \& Bacon.

Salen, K. (2008). Toward an ecology of gaming. In K. Salen (Ed.), The ecology of games: Connecting youth, games, and learning (pp. 1-20). Cambridge, MA: MIT Press.

Salen, K., Tekinbaş, K.S. \& Zimmerman, E. (2004). Rules of play: Game design fundamentals. Cambridge, MA: MIT Press.

Sanford, K. \& Hopper, T. (2009). Starting a program wide ePortfolio for development of teaching identity: Identifying learning stages of Learning Forum. Teacher Education Quarterly, Special Online Edition, 37(1), 1-28.

Semali, L.M. \& Kincheloe, J.L. (1999). Introduction: 'What is indigenous knowledge and why should we study it?' In L.M. Semali \& J.L. Kincheloe (Eds), What is indigenous knowledge? Voices from the academy. New York and London: Falmer Press.

Stenhouse, L. (1975). An introduction to curriculum research and development. London: Heinemann.

Stufflebeam, D.L. (1971). The relevance of the CIPP evaluation model for educational accountability. Journal of Research and Development in Education, 5, 19-25.

Stufflebeam, D.L. \& Shinkfield,A.J. (2007). Evaluation theory, models, and applications (Chapter 19). San Francisco, CA: Jossey-Bass.

Stufflebeam, D. L. (2003). The CIPP model for evaluation. In D.L. Stufflebeam \& T. Kellaghan (Eds), The international handbook of educational evaluation (Chapter 2). Boston, MA: Kluwer Academic Publishers.

Taba, H. (1962). Curriculum development: Theory and practice. New York, NY: Harcourt, Brace.

Tyler, R.W. (1949). Basic principles of curriculum and instruction. Chicago, IL: University of Chicago Press.

Urevbu, A.O. (1985). Integrating science and technology into a policy of lifelong education in Nigeria. International Journal of Lifelong Education, 4(4), 319-325.

Walker, D.F. (1971). A naturalistic model for curriculum development. School Review, 80(1), 51-67.

Vygotsky, L.S. (1978). Mind in society: The development of higher psychological process. Cambridge, MA: Harvard University Press. 
